\title{
Preparation and characterization of biosorbents and copper sequestration from simulated wastewater
}

\author{
M. Bansal • A. Mudhoo $\cdot$ V. K. Garg • \\ D. Singh
}

Received: 19 November 2012/Revised: 23 February 2013/Accepted: 21 April 2013/Published online: 17 May 2013

(C) Islamic Azad University (IAU) 2013

\begin{abstract}
This paper reports the potential of chemically treated wood chips to remove copper (II) ions from aqueous solution a function of $\mathrm{pH}$, adsorbent dose, initial copper (II) concentration and contact time by batch technique. The wood chips were treated with (a) boiling, (b) formaldehyde and (c) concentrated sulphuric acid and characterized by Fourier transform infrared spectroscopy, scanning electron microscopy and energy dispersive analysis X-ray. pH 5.0 was optimum with 86.1, 88.5 and $93.9 \%$ copper (II) removal by boiled, formaldehyde-treated and concentrated sulphuric acid-treated wood chips, respectively, for dilute solutions at $20 \mathrm{~g} \mathrm{~L}^{-1}$ adsorbent dose. The experimental data were analysed using Freundlich, Langmuir, Dubinin-Radushkevich and Temkin isotherm models. It was found that Freundlich and Langmuir models fitted better the equilibrium adsorption data and the adsorption process followed pseudo-second-order reaction kinetics. The results showed that the copper (II) is considerably
\end{abstract}

M. Bansal

Department of Civil Engineering, Punjab Technical University, Giani Zail Singh Campus, Bathinda, Punjab, India

A. Mudhoo $(\square)$

Department of Chemical and Environmental Engineering,

Faculty of Engineering, University of Mauritius,

Reduit, Mauritius

e-mail: ackmezchem@yahoo.co.uk

V. K. Garg

Department of Environmental Science and Engineering, Guru Jambheshwar University of Science and Technology, Hisar 125001, Haryana, India

D. Singh

Department of Civil Engineering, National Institute

of Technology, Kurukshetra 136119, India adsorbed on wood chips and it could be an economical option for the removal of copper from aqueous systems.

Keywords Copper - Wood - Adsorption - Sulphuric acid . Formaldehyde

\section{Introduction}

Heavy metal ions may be released into wastewater from various industries such as metal finishing, electroplating, automotive, battery manufacturing, steel industries, tannery, paint manufacturing and electronic industries (Wan Ngah and Hanafiah 2008). It has been reported that excessive intake of copper by humans may lead to severe mucosal irritation, hepatic and renal damage, capillary damage, gastrointestinal irritation and central nervous system irritation (Larous et al. 2005). Increasingly stringent discharge limits for heavy metals and their widespread uses threatening presence at hazardous waste sites have accelerated the search for advanced and economically attractive treatment technologies for their removal.

Conventionally, heavy metals removal from aqueous solution has commonly been carried out by chemical precipitation, solvent extraction, ion exchange, reverse osmosis or adsorption. Chemical precipitation, in particular, is the most prevalent method but not suitable for removing low concentration of heavy metal ions. But none of the method is complete because each method has its own limitations. Adsorption, with the selection of suitable adsorbents, can be an effective technique for the removal of heavy metals from wastewater (Rafatullah et al. 2009) and the air (Tirgar et al. 2011). Although adsorbents have high metal adsorption capacity, they are expensive and difficult to be separated from the wastewater after use. 
Therefore, a growing research interest has been developed in search of low-cost alternatives to these adsorbents (McKay et al. 1999; Veglio and Beolchini 1997; Gupta et al. 2009). These are typically residues from agriculture or industrial processes which have been used in the treatment of industrial wastewater or contaminated groundwater. The use of these residues has, in general, given the process the more common name of biosorption with the adsorbent nominated as biosorbent. Various biosorbents developed from agrowastes and used for heavy metals removal include rice straw (Gao et al. 2008), free algal biomass for biosorption of copper and zinc (Wan Maznah et al. 2012), removal of copper and zinc sunflower (Helianthus annuus), Chinese cabbage (Brassica campestris), cattail (Typha latifolia), and reed (Phragmites communis) as reported by Yeh et al. (2011), biomass of Desmostachy bipannata (Kush, a religious plant of Hindus) (Kour et al. 2012), peanut shell (Witek-Krowiak et al. 2011), Peganum harmala seeds as a biosorbent to remove lead, zinc and cadmium ions from contaminated water (Zamani et al. 2013), seaweed (Basha et al. 2008), wood and bark (Mohan et al. 2007), tea waste (Malkoc and Nuhoglu 2007), maize corn cob, jatropha oil cake, sugarcane bagasse (Dos Santos et al. 2011), raw and treated Agave salmiana bagasse (Velazquez-Jimenez et al. 2013), sawdust (Hashem et al. 2013; Memon et al. 2005), rice husk (Kumar and Bandyopadhyay 2006), marine algal biomass, bagasse fly ash (Rameshraja et al. 2012), wool, olive cake, sawdust, pine needles, Aleppo pine adsorbent (Benyoucef and Amrani 2011), almond shells, impregnated palm shell activated carbon with polyethyleneimine (Owlad et al. 2010), Camellia oleifera Abel shells ( $\mathrm{Lu}$ et al. 2013), cactus leaves, and charcoal and pine bark (Al-Asheh et al. 2000).

The present study was conducted to investigate the removal of copper (II) from aqueous solution by wood chips in their natural and chemically treated (with formaldehyde and sulphuric acid) forms as low-cost adsorbent derived from wood waste biomass. This by-product is available in large amount in India and other countries from wood processing industries. It is either used as fuel in brick kilns, a packing material or for insulation and is available at negligible price. The effects of $\mathrm{pH}$, adsorbent dose, concentration of metal ions and contact time have been investigated. The linearized forms of the Langmuir, Freundlich, Temkin and Dubinin-Radushkevich adsorption isotherm models were used to fit the equilibrium isotherm (Pehlivan et al. 2012), and the adsorption kinetics was determined using pseudo-first-order and pseudo-second-order models. The data obtained are expected to be of use to environmental engineers in the design of heavy-metal-containing wastewater treatment systems.

\section{Materials and methods}

Biosorbent preparation and $\mathrm{Cu}(\mathrm{II})$ solution

The pretreatments on the wood chips were done for the following reasons (Mudhoo and Seenauth 2011): to remove inherent colour of the wood as colour may interfere with analysis of the $\mathrm{Cu}^{2+}$, functional groups within the wood get opened, and hence, there is more adsorption possibility, and the active surface area of the wood is increased, thereby liberating more active binding sites.

\section{Pre-boiled wood chips (BWCs)}

Wood chips were procured from a local timber mill located at Kurukshetra (Haryana, India). The collected wood chips were dried in natural sunlight $\left(40-45^{\circ} \mathrm{C}\right)$, and impurities were separated manually. The cleaned wood chips were boiled with distilled water for $5 \mathrm{~h}$ to remove inherent coloured compounds in the wood and filtered (Bansal et al. 2009). The residue so obtained was dried at $80{ }^{\circ} \mathrm{C}$ in hot air oven (MSW2011, Mac, India) for $24 \mathrm{~h}$. The oven-dried residue was ground and sieved through the sieves of $300 \mu \mathrm{m}$ size. The final powdered material was stored in airtight plastic containers for further use in the adsorption experiments.

\section{Formaldehyde-treated wood chips (FWC)}

To immobilize the colours and water soluble substances present in the wood which could otherwise interfere with the adsorption of copper ions onto the active binding sites (Ahmad et al. 2009), the wood chips were treated with $1 \%$ formaldehyde in the ratio of 1:5 (wood chips: formaldehyde, w/v) at room temperature $\left(25 \pm 1{ }^{\circ} \mathrm{C}\right)$ for $24 \mathrm{~h}$ (Bansal et al. 2009; Ahmad et al. 2009). The formaldehyde-treated wood chip residues were filtered, double washed with distilled water to remove any free residual formaldehyde molecules and dried at $60^{\circ} \mathrm{C}$ in a hot air oven for $24 \mathrm{~h}$ (MSW-2011, Mac, India). The resulting material was ground and then sieved through the sieves of $300 \mu \mathrm{m}$ size. The final powder was stored in airtight plastic containers for the subsequent experimental adsorption runs.

\section{Sulphuric acid-treated wood chips (SWC)}

Dried wood chips were washed with deionized water until all leachable impurities were removed. The samples were then treated with concentrated $\mathrm{H}_{2} \mathrm{SO}_{4}(50 \%)$ in a ratio of 2:1 (acid volume: weight of wood chips) and allowed to get carbonized at $150{ }^{\circ} \mathrm{C}$ in hot air oven for $24 \mathrm{~h}$ (MSW-2011, Mac, India). The carbonized acid-treated wood chips were then soaked in deionized water until solution $\mathrm{pH}$ was stable (Bansal et al. 2009). Afterwards, the wood chips carbon 
(SWC) so obtained was soaked in $2 \% \mathrm{NaHCO}_{3}(\mathrm{w} / \mathrm{v})$ till any residual acid left was removed. Finally, the samples were dried in hot air oven at $110{ }^{\circ} \mathrm{C}$, cooled, ground and sieved in the size of 300 microns and stored in airtight containers for further use.

\section{$\mathrm{Cu}(\mathrm{II})$ solutions}

In distilled water, $3.92 \mathrm{~g}$ of copper sulphate $\left(\mathrm{CuSO}_{4}\right)$ was dissolved, and the final volume of solution was made $1.0 \mathrm{~L}$. This solution contained divalent copper ion concentration of $1,000 \mathrm{mg} \mathrm{L}^{-1}$. It was further diluted with distilled water to produce solutions of different concentrations of copper (II) as desired in experiments. $\mathrm{pH}$ of the solutions was adjusted using $0.01 \mathrm{M} \mathrm{NaOH} / 0.01 \mathrm{M} \mathrm{HCl}$ using $\mathrm{pH}$ metre (Model pHep, Hanna Instruments, calibrated with buffers of $\mathrm{pH} 4.0,7.0$ and 9.2).

Characterization of biosorbents and speciation of copper ions

Fourier transform infrared spectroscopy (FTIR) was used to determine the vibration frequency changes in the functional groups in the biosorbents before and after the adsorption experiments. The spectra of biosorbents were measured by an FTIR spectrometer FTIR-8400S, Shimadzu, Japan within the range of $400-4,000 \mathrm{~cm}^{-1}$ wave number. The surface morphology and metal ion distribution on biosorbents surface were visualized by scanning electron microscopy (SEM). The SEM images of suitable magnification and resolution being obtained using a model Quanta 200 FEG, FEI, Netherlands. Energy dispersive analysis X-ray (EDAX) measurements of the samples (with and without metal ions) for qualitative analyses of the elemental constitution of the various samples were also measured by using model Quanta 200 FEG, FEI, Netherlands.

\section{Adsorption experiments}

The adsorption experiments were conducted based on procedures adapted from the experimental methods previously described in Bansal et al. (2009). Batch experiments were carried out at various $\mathrm{pH}(2-7)$, adsorbent dose (4$20 \mathrm{~g} \mathrm{~L}^{-1}$ ) and stirring speed (180 rpm) for a contact time of $180 \mathrm{~min}$. For each batch experiment, $100 \mathrm{~mL}$ copper (II) solution of $100 \mathrm{mg} \mathrm{L}^{-1}$ concentration was used. After setting the $\mathrm{pH}$ to the desired value for each run and adding desired amount of adsorbent, the mixture was agitated on orbital shaker (Orbitak, Scigenics Biotech, India) for $180 \mathrm{~min}$. After this step, the mixture was centrifuged in a centrifuge (R-24, Remi, India) to separate the adsorbent from supernatant liquid. The residual concentration of copper ion in the supernatant liquid was determined using a
Shimadzu 6300 atomic absorption spectrophotometer (AAS). All experiments were replicated thrice for all the adsorbents and results were averaged. The removal percentage $(R \%)$ of copper was calculated for each run using the following equation:

$R(\%)=\frac{\left(C_{\mathrm{i}}-C_{\mathrm{e}}\right)}{C_{\mathrm{i}}} \times 100$

where $C_{\mathrm{i}}$ and $C_{\mathrm{e}}$ are the initial and final concentration of copper in the solution, respectively. The adsorption capacity of an adsorbent which is obtained from the mass balance on the sorbate in a system with solution volume $V(\mathrm{~L})$ is often used to generate the experimental adsorption isotherms (Bansal et al. 2009). The adsorption capacities $\left(q_{\mathrm{e}}\right)$ of all the adsorbents for each concentration of copper (II) ions at equilibrium were calculated using Eq. (2).

$q_{\mathrm{e}}(\mathrm{mg} / \mathrm{g})=\frac{\left(C_{\mathrm{i}}-C_{\mathrm{e}}\right) V}{M}$

where $M$ is the mass of adsorbent (g) used.

\section{Kinetics}

Kinetics model studies enable the calculation of mass transfer coefficients. They also provide equilibrium time for the different initial metal ion concentrations. Different conical flasks with same (one) initial concentration maintained with optimized $\mathrm{pH}$, dosages and temperature were agitated at $180 \mathrm{rpm}$ taking time of start as $t_{\mathrm{o}}$. Samples were withdrawn at fixed time intervals up to $180 \mathrm{~min}$ from the flasks in triplicates and analysed for residual copper ion concentrations as described earlier.

\section{Results and discussion}

Wood chips are a waste biomass produced at timber mills. Wood chips typically contain cellulose, sugars and lignin (Vinodhini and Das 2009), and this composition strongly tends to make it an effective biosorbent for heavy metal cations. Since wood chips are available in plenty and have a high potential as adsorbent, the present study has been conducted to probe its adsorption behaviour for divalent copper ions from aqueous solutions.

Fourier transform infrared (FTIR) analysis of adsorbents

The FTIR spectra of biosorbents prepared from wood chips (BWC, FWC and SWC) before and after sorption of copper (II) ions (Fig. 1) were used to determine the vibrational frequency changes in the functional groups in the biosorbents. The spectra of biosorbents were measured within the 
range of $400-4,000 \mathrm{~cm}^{-1}$ wavenumber (Bansal et al. 2009). The spectra were plotted using the same scale on the transmittance axis for all the biosorbents before and after biosorption. From Fig. 1, it is observed that the FTIR spectra of the biosorbents display a number of peaks, indicating the complex nature of the studied biosorbents. Fundamental peaks of all the biosorbents prepared from wood chips before and after use (metal loaded) are given in Table 1. From these data, it became evident that hydroxide $(-\mathrm{OH})$, primary and secondary amines $(\mathrm{C}-\mathrm{N})$ and amide $(\mathrm{N}-\mathrm{H})$, lignin aromatic $(\mathrm{C}=\mathrm{O}), \mathrm{C}-\mathrm{H}$ group and aromatic compound groups were present on the surface of BWC, FWC and SWC. Ofomaja et al. (2010) have equally suggested that the main functional group present in Mansonia wood sawdust and participating in the adsorption of copper was -OH. The shift and disappearance of these groups wavelength indicated participation of this functionality in metal binding. The possible biosorption mechanisms of the copper ions on these biosorbents (BWC, FWC and SWC) may be due to physical adsorption, complexation with functional groups, ionic exchange, surface precipitations and chemical reaction with surface sites on the oxidized carbons produced from the chemical treatments. The changes in observed from the FTIR spectra (Fig. 1) confirmed the complexation of copper (II) ions with the functional groups present in the biosorbents. Tangsathitkulchai et al. (2009) reported that liquid oxidation with the sulphuric acid led to an increase in acidic group concentration, with carboxylic acid normally showing the largest percentage increase. Tangsathitkulchai et al. (2009) subsequently found that the increased contents of acidic groups on oxidized carbons greatly enhanced the adsorption capacity of heavy metal ions. In this study, the treatment of the native wood chips with sulphuric acid would most plausibly have produced oxidized carbons. Pehlivan et al. (2012) equally found that carboxyl groups present on the surface of the citric acid modified barley straw were primarily responsible for the sorption of copper (II) ions.

\section{Scanning electron microscopy and EDAX of adsorbents}

Scanning electron micrograph (SEM) indicates changes in surface microstructures and morphology of the biosorbent. The energy dispersive spectrum of X-ray (EDAX) identifies and provides such results that supplement the SEM micrographs by depicting the peaks of the heavy metals that have been actually adsorbed on the biosorbent surface. In this respect, the results of the SEM and EDAX have to be interpreted in a pair in order to support the fact that adsorption of the heavy metal does take place on the adsorbent. SEM and EDAX analyses were carried out on the biosorbents before and after equilibration with the copper (II) ion solutions. The SEM micrographs of native
BWC, FWC and SWC and copper (II) ions loaded biosorbents at $\times 1,000$ magnifications are given in Fig. 2. SEM micrographs of BWC surfaces before and after the biosorption of copper (II) ions indicated the presence of copper (II) ions (Fig. 2a, b). Native BWC showed irregular groove and ridges in fibrous networks which are considered essential for the accessibility of heavy metals ions to the biosorbent surface and eventually to the active sites. The SEM micrographs in Fig. 2d, $\mathrm{f}$ indicate the presence of copper (II) ions in the form of ridges and layers of copper particle agglomerates over the surface of metal loaded biosorbents (FWC and SWC). These layers were originally absent on the original biosorbent before loading of metal ions (Fig. 2c, e). Musyoka et al. (2011), Salam et al. (2011), Da'na and Sayari (2011), Zhang et al. (2011) and Cui et al. (2011) have equally conducted SEM analyses to study the changes in the morphology of adsorbents tested for the removal of metal ions. Salam et al. (2011) reported similar surface modifications when studying multi-walled carbon nanotubes modified with chitosan for the removal of copper, zinc, cadmium and nickel ions from aqueous solution. Da'na and Sayari (2011) studied the adsorption of copper on amine-functionalized SBA-15 prepared by cocondensation, and the SEM images obtained indicated rodshaped particles aggregated into bundles. In their study of the determination of trace copper, manganese and nickel in environmental water samples, Cui et al. (2011) observed similar agglomerates of heavy metals in the form of layers and ridges on alumina hollow fibre. Zhang et al. (2011) have equally reported similar layered accumulation of metal ions when testing highly porous biodegradable monoliths strengthened by graphene oxide for their adsorption capacity of metal ions.

Energy dispersive spectrum of X-ray (EDAX) measurements of the BWC, FWC and SWC with and without metals ions was also undertaken for qualitative analysis of the elemental constitution. The EDAX spectrum for native as well as for copper (II) ions loaded biosorbents are given in Fig. 3. The biosorbents equilibrated with metals ions solution showed distinct peaks of copper (II) ions, indicating that ions of this specific metal had been actually sorbed onto the surface of the biosorbents. The appearance of gold in the spectra was due to the fact that the biosorbents were coated with gold prior to analysis. EDAX analysis therefore provided direct and supportive evidence for the specific biosorption of copper (II) ions onto biosorbents.

\section{Effect of $\mathrm{pH}$ on $\mathrm{Cu}(\mathrm{II})$ removal}

The $\mathrm{pH}$ of an aqueous solution is an important controlling parameter in the process of biosorption. Solution $\mathrm{pH}$ affects both aqueous chemistry and surface binding sites of the biosorbent (Ofomaja et al. 2010). The effect of $\mathrm{pH}$ on the 

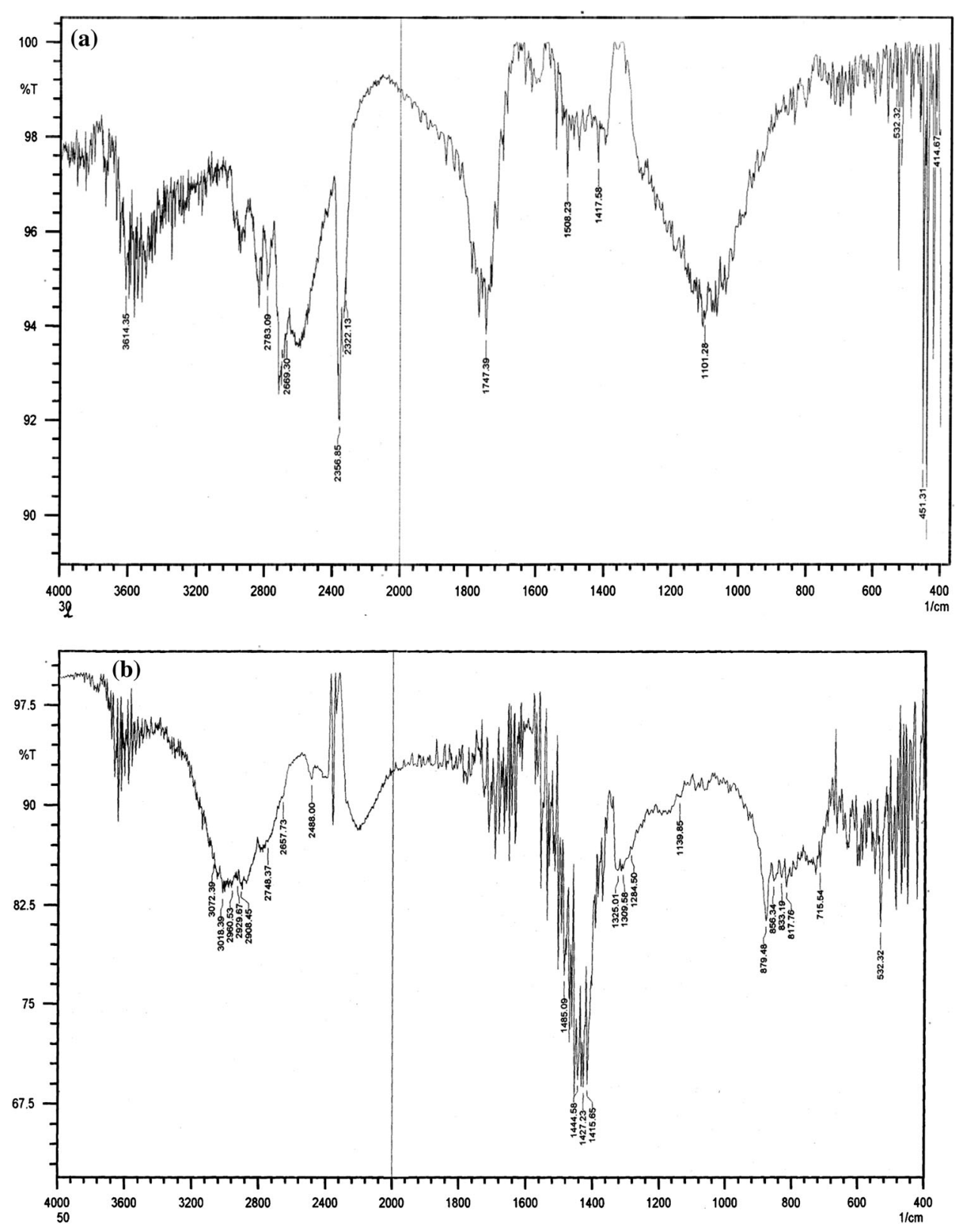

Fig. 1 a FTIR of native BWC, b FTIR of copper (II) ions loaded BWC, $\mathbf{c}$ FTIR of native FWC, d FTIR of copper (II) ions loaded FWC, e FTIR of native SWC and $\mathbf{f}$ FTIR of copper (II) ions loaded SWC

biosorption of copper (II) by BWC, FWC and SWC biosorbents is presented in Fig. 4. Experiments were not conducted for $\mathrm{pH}$ higher than 5.0 because of the observed precipitation of the copper (II) as its hydroxide (Benaïssa and Elouchdi 2011). Copper exists as $\mathrm{Cu}^{2+}, \mathrm{Cu}(\mathrm{OH})^{+}$and $\mathrm{Cu}(\mathrm{OH})_{2}$ in aqueous solution (Ofomaja and Naidoo 2011). At low solution $\mathrm{pH}\left(\mathrm{pH} 2\right.$ and 5.5), $\mathrm{Cu}^{2+}$ and $\mathrm{Cu}(\mathrm{OH})^{+}$are the dominant species in aqueous solution (Zhu et al. 2008). In agreement with the present study's overall results and observations made on effect of $\mathrm{pH}$ on copper adsorption, Ofomaja and Naidoo (2011) equally remarked that as the initial solution $\mathrm{pH}$ increases, $\mathrm{H}^{+}$ions competition reduces and copper (II) removal increases from $\mathrm{pH} 2$ to 5. Thus, after an initial $\mathrm{pH} 5.0$, the decreasing concentration of $\mathrm{Cu}^{2+}$ and $\mathrm{Cu}(\mathrm{OH})^{+}$at higher $\mathrm{pH}$ and the appearance of $\mathrm{Cu}(\mathrm{OH})_{2}$ was resulting in lower adsorption capacities for all samples. As evident from the results, copper (II) biosorption increased with increase in the $\mathrm{pH}$ from 2.0 to 5.0, but maximum biosorption was observed at $\mathrm{pH}$ 5.0. Hence, in this study, a pH 5.0 was considered as the optimum $\mathrm{pH}$ with $86.1,88.5$ and $93.9 \%$ copper (II) removal by BWC, FWC and SWC, respectively. Ofomaja et al. (2010) equally 

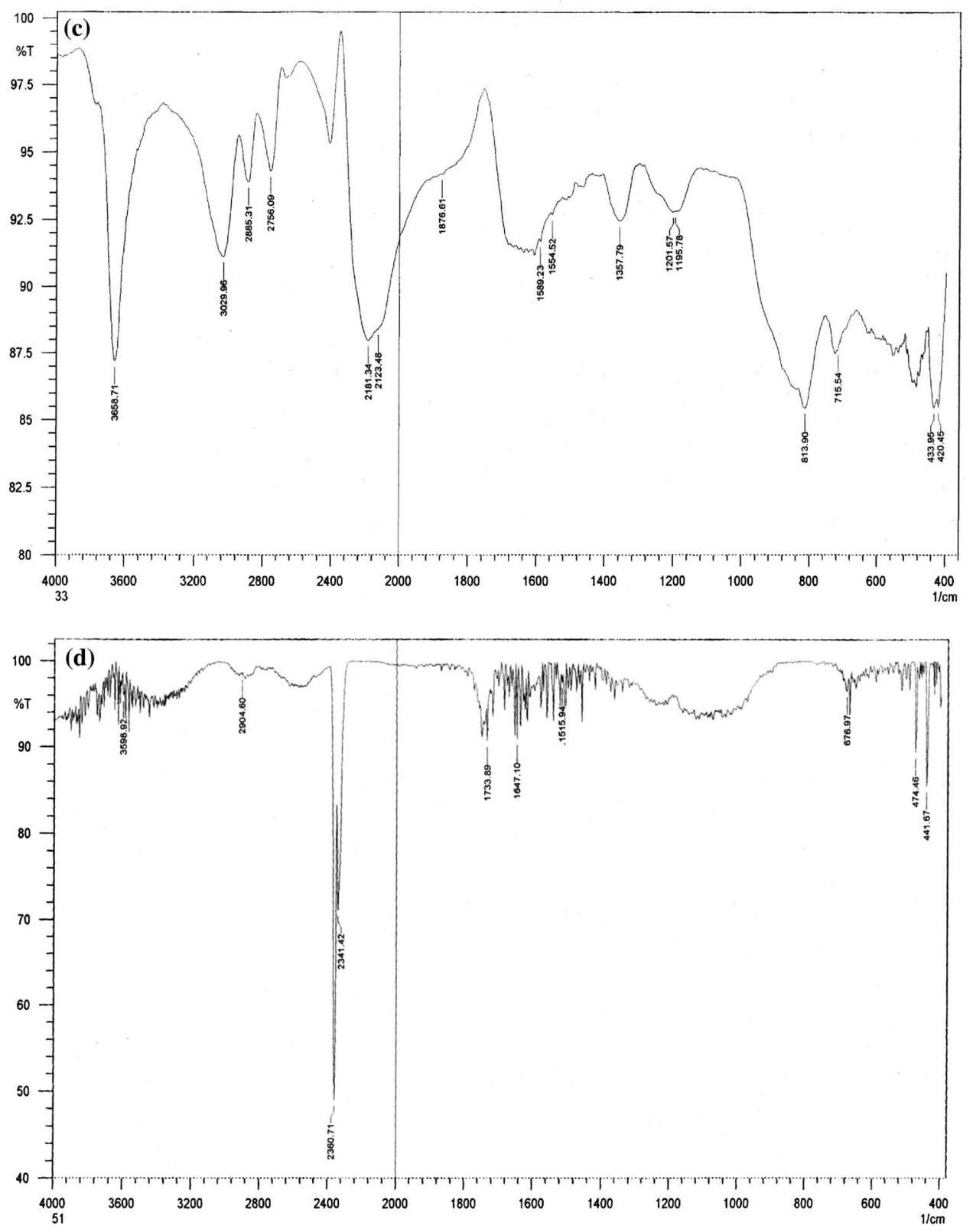

Fig. 1 continued

observed that between a solution $\mathrm{pH}$ of 5.0 and 6.0, the rate of increase in copper ions uptake reduced, and as result, a $\mathrm{pH} 6.0$ was chosen for further studies. The $\mathrm{pH}$ of the biosorption medium affects the solubility of metal ions and the ionization state of the functional groups. Cerino Córdova et al. (2011) stated that functional groups of biosorbents can be protonated or deprotonated depending on their dissociation constant that is function of the solution $\mathrm{pH}$. Because of high proton concentration at lower $\mathrm{pH}$, heavy metal biosorption decreases due to the positive charge density on metal binding sites, that is, hydrogen ions compete effectively with metal ions in binding to the sites. At higher $\mathrm{pH}$, the negative charge density on the biosorbent surface increases due to deprotonation of the metal binding sites. The metal ions then compete more effectively for available binding sites, which increases biosorption (Kapoor and Viraraghvan 1997).

\section{Effect of adsorbent dose on $\mathrm{Cu}(\mathrm{II})$ removal}

The effect of biosorbents dose on biosorption of copper (II) ions by BWC, FWC and SWC is reported in Fig. 5. From 

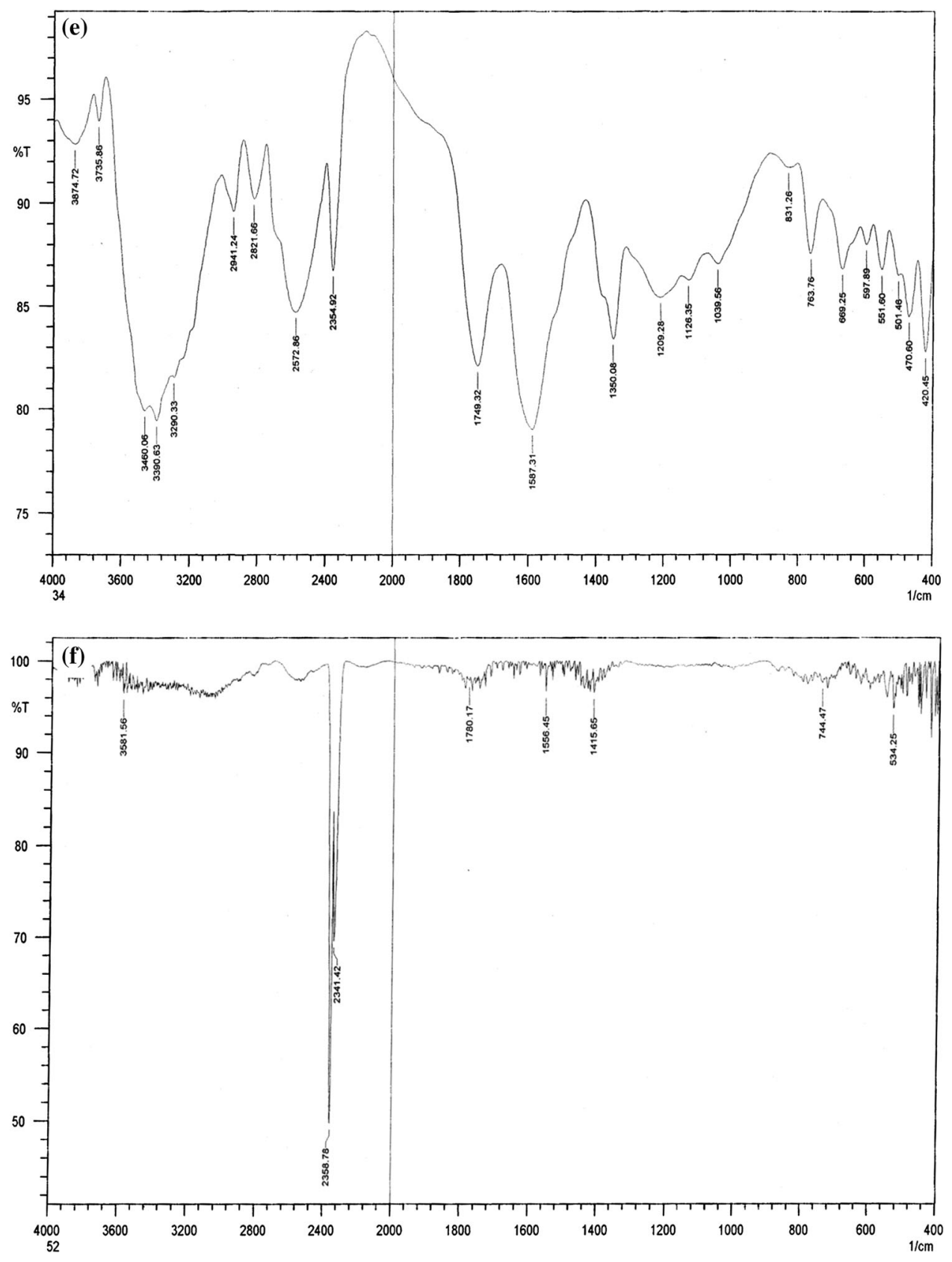

Fig. 1 continued

these results, it may be observed that copper (II) ions removal increased from 52.4 to $86.1 \%$ for BWC, 53.5 to $88.5 \%$ for FWC and 73.8 to $93.9 \%$ for SWC with increase in biosorbents dosage from 4.0 to $20.0 \mathrm{~g} \mathrm{~L}^{-1}$. The increases in percentage removal of copper (II) ions increased with increasing biosorbent dose could be attributed to the fact that with increases in biosorbent dose, more and more surface with active binding sites became available for the copper (II) ions to be adsorbed. This ultimately increased the overall rate of biosorption. The slow increase in removal which then followed was due to attainment of equilibrium between biosorbate and biosorbent at the existing operating conditions (Bai and Abraham 2001).

Effect of initial metal ion concentration and contact time

At the initial stage of adsorption, the surface of the adsorbent is free of copper (II) ions, and large amounts of copper (II) ion species move across from the solution to the adsorbent surface. As copper (II) ions accumulate on the surface near the active binding sites, part of the adsorbed 
Table 1 Some fundamental FTIR frequencies in native and metal loaded saw dust-based biosorbents

\begin{tabular}{llllllll}
\hline Biosorbents (native and metal loaded) & \multicolumn{2}{l}{ Possible assignments $\left(\mathrm{cm}^{-1}\right)$} \\
\cline { 2 - 8 } & - $\mathrm{OH}$ & $\mathrm{C}-\mathrm{H}$ & $\mathrm{C}=\mathrm{O}$ & $\mathrm{N}-\mathrm{H}$ & $-\mathrm{CH}_{3}$ & $\mathrm{C}-\mathrm{N}$ & Bending vibrations \\
\hline BWC & $3,614.35$ & $2,783.09$ & $1,747.39$ & $1,508.23$ & - & $1,101.28$ & 451.31 \\
BWC Cu(II) & - & $2,748.37$ & - & $1,485.09$ & - & $1,139.85$ & 532.32 \\
FWC & $3,658.71$ & $2,885.31$ & $1,589.23$ & $1,554.52$ & $1,357.79$ & $1,195.78$ & $433.95,715.54$ \\
FWC Cu(II) & $3,598.92$ & $2,904.60$ & $1,647.10$ & $1,515.94$ & - & - & $441.67,676.97$ \\
SWC & $3,460.06$ & $2,821.66$ & $1,749.32$ & $1,508.23$ & - & $1,222.79$ & $478.31,673.11$ \\
SWC Cu(II) & $3,581.56$ & - & $1,780.17$ & $1,556.45$ & - & - & $534.25,744.47$ \\
\hline
\end{tabular}
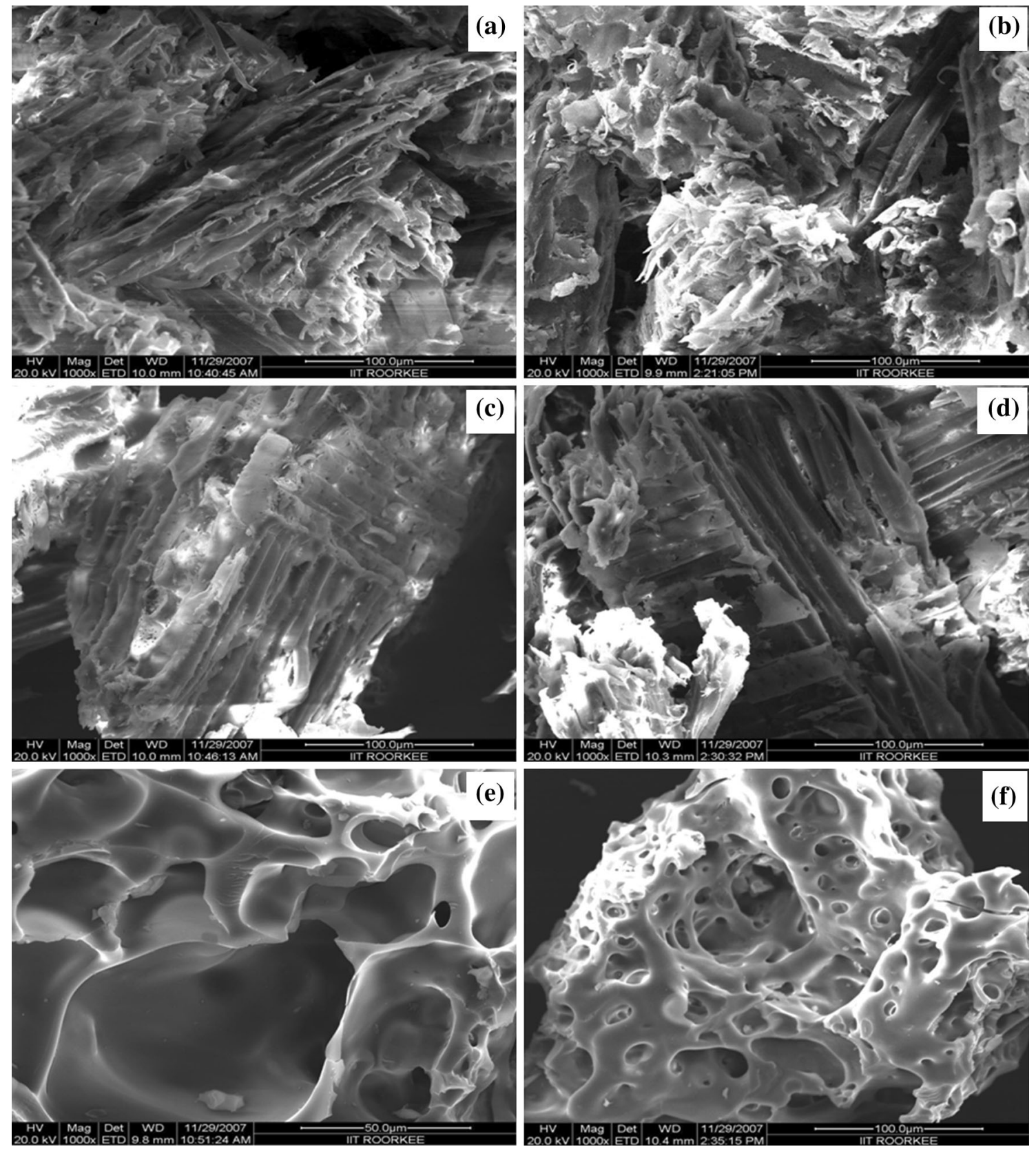

Fig. 2 a SEM of native BWC, b SEM of copper (II) ions loaded BWC, c SEM of native FWC, d SEM of copper (II) ions loaded FWC, e SEM of native SWC and $\mathbf{f}$ SEM of copper (II) ions loaded SWC 
copper (II) ions are desorbed from these sites back into the bulk of the solution till the rate of adsorption is matched by the rate of desorption and equilibrium is reached (Ofomaja and Naidoo 2011). The effect of initial metal ion concentration on copper (II) ions removal by BWC, FWC and SWC for this study is given in Fig. 6. During the
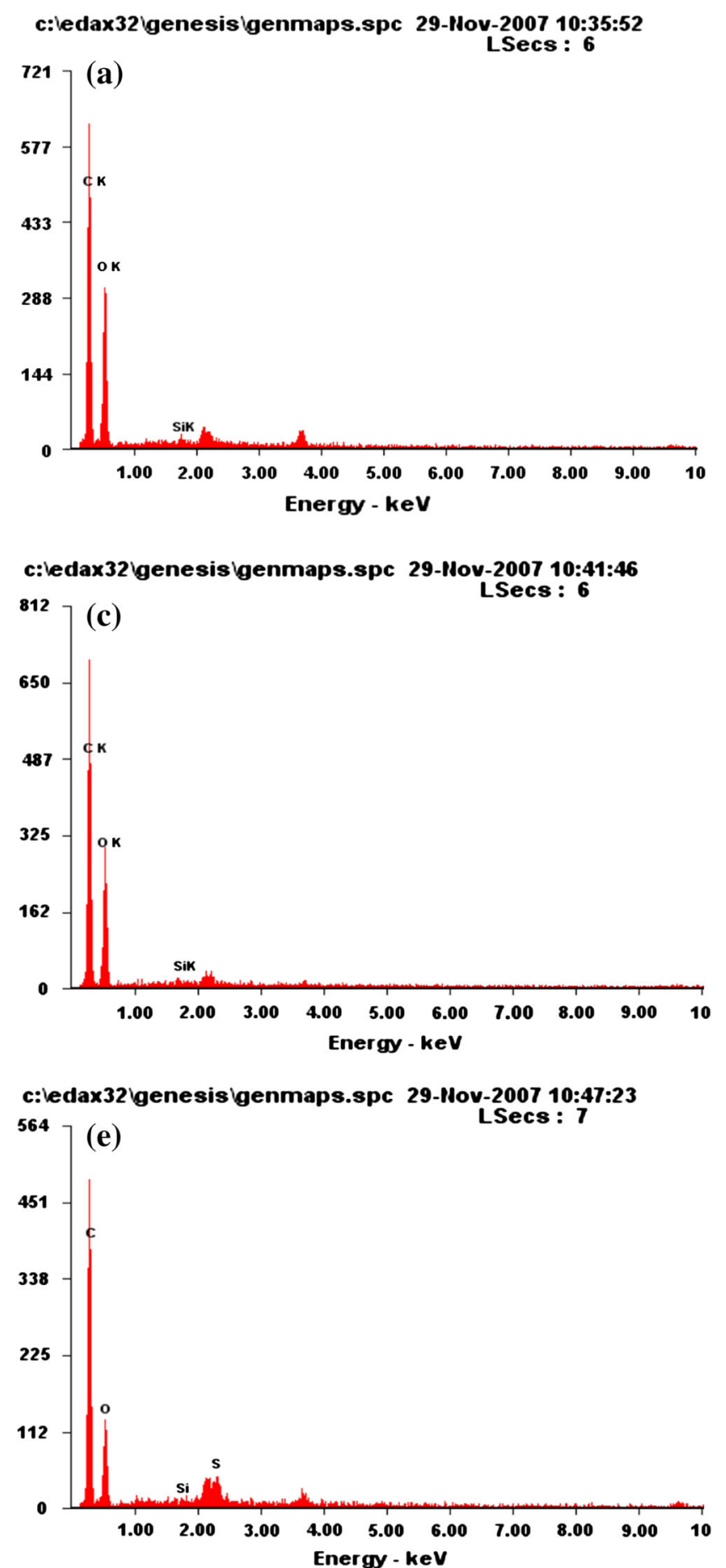

experiments, two separate behaviours were observed in the copper (II) adsorption profiles for all samples. These behaviours consisted in an initial rapid copper (II) ion uptake up till 5-6 $\mathrm{mg} \mathrm{L}^{-1}$ and a subsequently much slower removal of copper (II) ions from solutions beyond $8 \mathrm{mg} \mathrm{L}^{-1}$. Biosorption of copper (II) ions decreased from
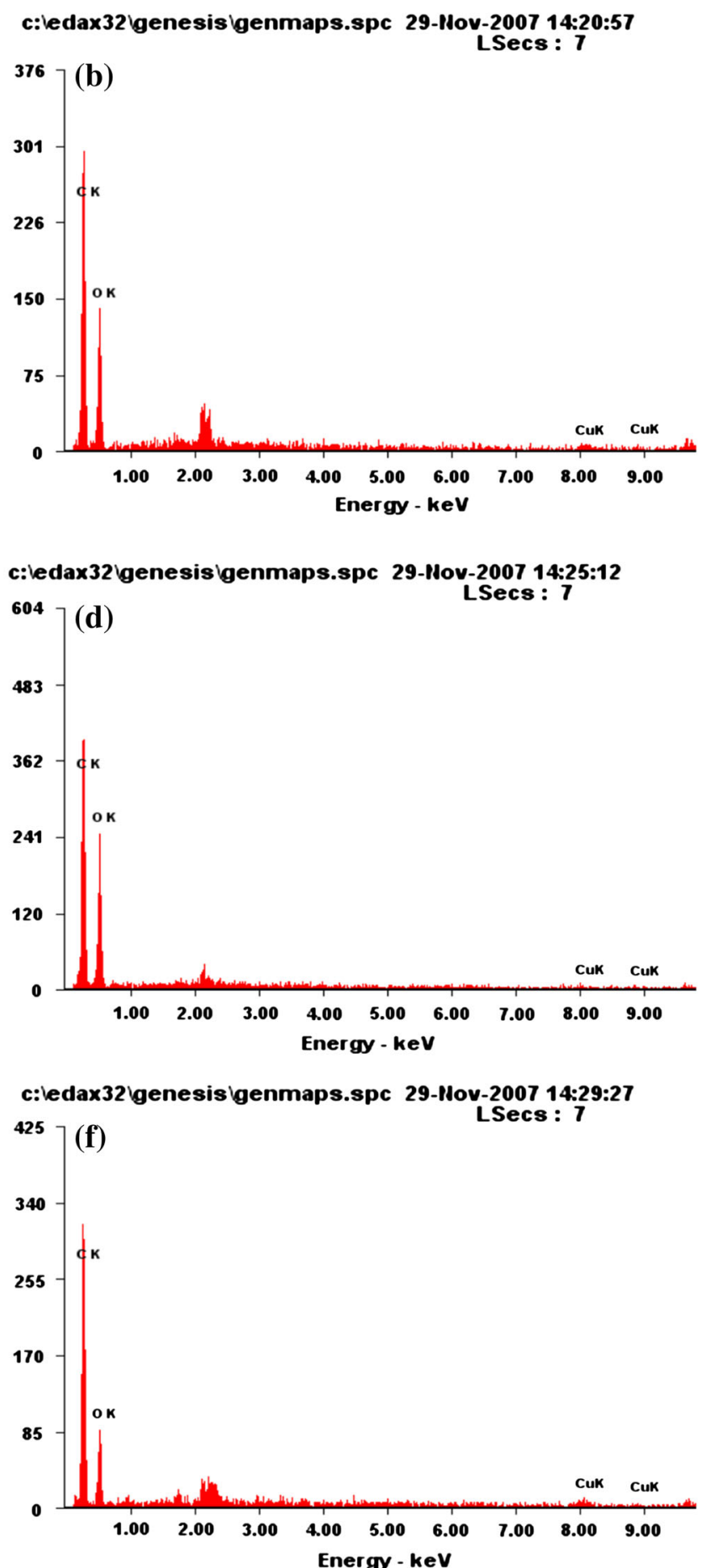

Fig. 3 a EDAX of native BWC, b EDAX of copper (II) ions loaded BWC, $\mathbf{c}$ EDAX of native FWC, $\mathbf{d}$ EDAX of copper (II) ions loaded FWC, e EDAX of native SWC and $\mathbf{f}$ EDAX of copper (II) ions loaded SWC 


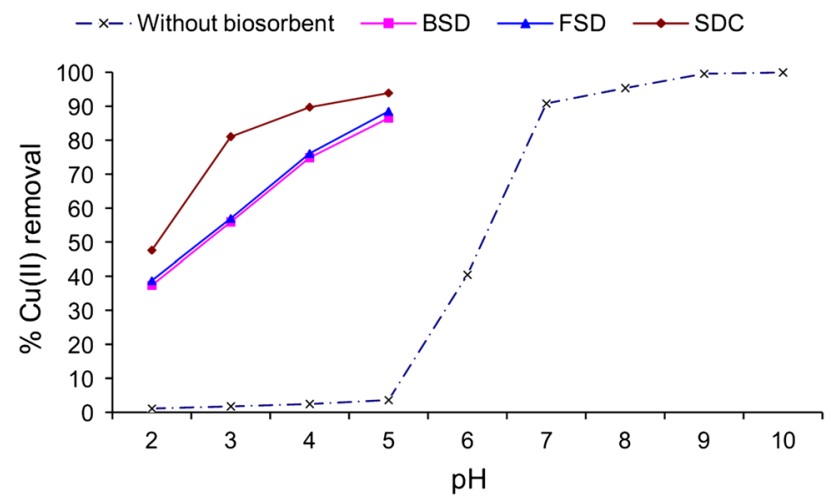

Fig. 4 Effect of pH on copper (II) ions removal by BWC, FWC and SWC (copper (II) ions conc $=100 \mathrm{mg} \mathrm{L}^{-1}$; biosorbent dose $=$ $20.0 \mathrm{~g} \mathrm{~L}^{-1}$; contact time $=180 \mathrm{~min}$; stirring speed $=180 \mathrm{rpm}$; temp $=25^{\circ} \mathrm{C}$ )

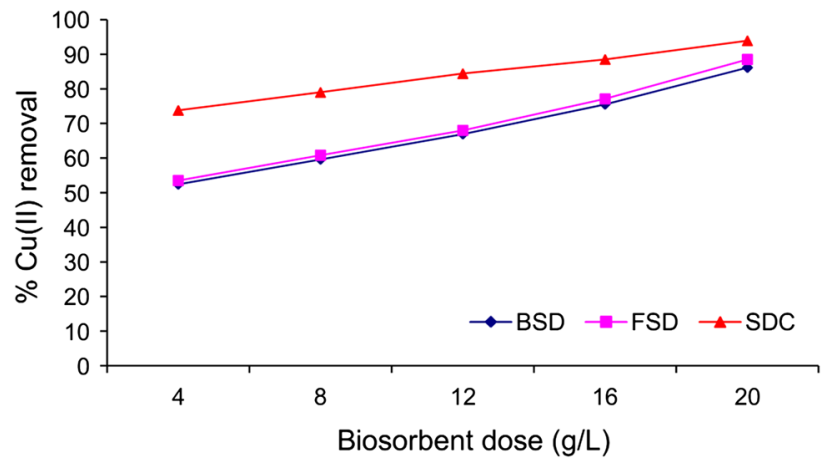

Fig. 5 Effect of biosorbent dose on copper (II) ions removal by BWC, FWC and SWC (copper (II) ions conc $=100 \mathrm{mg} \mathrm{L}^{-1}$; $\mathrm{pH}=5.0 ;$ contact time $=180 \mathrm{~min} ; \quad$ stirring speed $=180 \mathrm{rpm}$; temp $=25^{\circ} \mathrm{C}$ )

96.4 to $60.0 \%$ for BWC, 97.7 to $61.5 \%$ for FWC and 99.2 to $66.7 \%$ for SWC with the increase in copper (II) ions concentration from 5 to $500 \mathrm{mg} \mathrm{L}^{-1}$. At low initial concentration of metal ions, more binding sites were available. However, as the concentration increased, the number of ions competing for available binding sites in the biomass equally increased and the net biosorption rate of the copper (II) decreased (Garg et al. 2004).

The effect of contact time on copper (II) ions removal by BWC, FWC and SWC is given in Fig. 7. It was observed that removal of copper (II) ions increased from 36.9 to $86.1 \%$ for BWC, 38.0 to $88.5 \%$ for FWC and 45.6 to $93.9 \%$ for SWC with increase in contact time from 10 to $180 \mathrm{~min}$. There was no appreciable increase in copper (II) removal after the optimum time of $120 \mathrm{~min}$. This could be explained on basis of the fact that biosorbate molecules attain equilibrium at particular dose, $\mathrm{pH}$, temperature and contact time (Anderson et al. 1987). Similar observations have been made by Grimm et al. (2008), Dang et al. (2009) and Benaïssa and Elouchdi (2011).

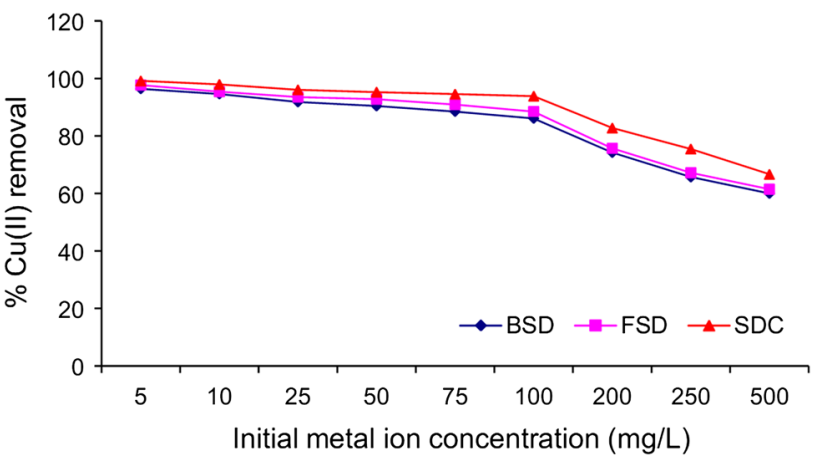

Fig. 6 Effect of initial metal ion concentration on copper (II) ions removal by BWC, FWC and SWC (biosorbent dose $=20.0 \mathrm{~g} \mathrm{~L}^{-1}$; $\mathrm{pH}=5.0 ;$ contact time $=180 \mathrm{~min} ;$ stirring speed $=180 \mathrm{rpm}$; temp $=25^{\circ} \mathrm{C}$ )

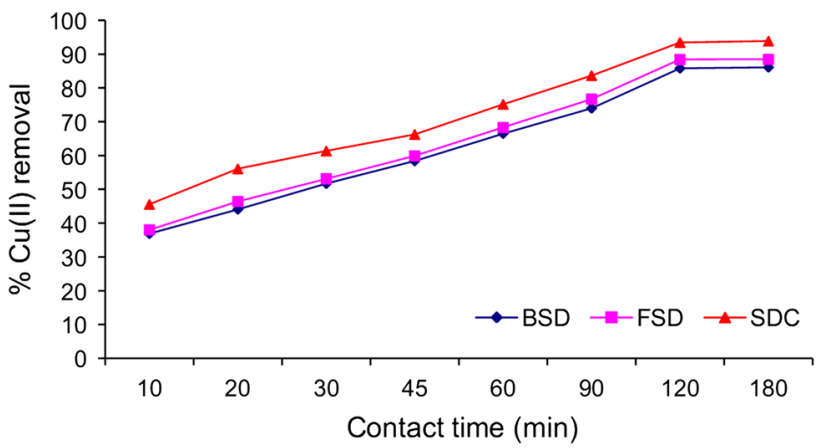

Fig. 7 Effect of contact time on copper (II) ions removal by BWC, FWC and SWC (copper (II) ions conc $=100 \mathrm{mg} \mathrm{L}^{-1}$; $\mathrm{pH}=5.0$; biosorbent $\quad$ dose $=20.0 \mathrm{~g} \mathrm{~L}^{-1} ; \quad$ stirring $\quad$ speed $=180 \mathrm{rpm}$; temp $=25{ }^{\circ} \mathrm{C}$ )

\section{Adsorption isotherms}

The distribution of metal ions between liquid and solid phases is generally described by Langmuir, Freundlich, Dubinin-Radushkevich and Temkin isotherms models. The isotherm constants were calculated from the slopes and intercepts of these curves and based on the linearized forms of these four models. Values of these constants are given in Table 2. The maximum adsorption capacity was 15.53, 15.53 and $16.86 \mathrm{mg} \mathrm{g}^{-1}$ for BWC, FWC and SWC, respectively. The results showed that the maximum adsorption capacity of BWC, FWC and SWC was all comparable. The values of the determination coefficient, $R^{2}$, for Langmuir equations for three biosorbents were as follows: BWC 0.9005, FWC 0.8998 and SWC 0.9276. Values of $R^{2}$ were not close to unity for BWC, FWC and SWC, thereby indicating the low efficacy of fitting Langmuir model to the equilibrium data. Values of $R_{\mathrm{L}}$ were calculated for BWC, FWC and SWC using Eq. 3 where $b$ is the Langmuir constant $\left(\mathrm{L} \mathrm{mg}^{-1}\right)$ and $C_{\mathrm{o}}\left(\mathrm{mg} \mathrm{L}^{-1}\right)$ is 
Table 3 Separation factor $\left(R_{\mathrm{L}}\right)$ values for BWC, FWC and SWC

\begin{tabular}{llll}
\hline $\begin{array}{l}\text { Initial } \mathrm{Cu}(\mathrm{II}) \text { ion } \\
\text { concentration }\left(\mathrm{mg} \mathrm{L}^{-1}\right)\end{array}$ & \multicolumn{3}{l}{ Separation factor $\left(R_{\mathrm{L}}\right)$} \\
\cline { 2 - 4 } & BWC & FWC & SWC \\
\hline 5 & 0.87 & 0.87 & 0.77 \\
10 & 0.76 & 0.76 & 0.63 \\
25 & 0.56 & 0.56 & 0.40 \\
50 & 0.39 & 0.39 & 0.25 \\
75 & 0.30 & 0.30 & 0.18 \\
100 & 0.24 & 0.24 & 0.14 \\
200 & 0.14 & 0.14 & 0.078 \\
250 & 0.11 & 0.11 & 0.063 \\
500 & 0.06 & 0.06 & 0.033 \\
\hline
\end{tabular}

the initial concentration of copper (II) ions. The $R_{\mathrm{L}}$ values varied between 0 and 1 indicating favourable adsorption of copper (II) ions onto BWC, FWC and SWC (Table 3).

$R_{\mathrm{L}}=\frac{1}{\left(1+b C_{\mathrm{o}}\right)}$

The Freundlich isotherm for the sorption of copper by BWC, FWC and SWC was investigated in a batch process. The isotherms for WC, FWC and SWC were obtained using initial copper (II) ions concentrations in the range of $5-500 \mathrm{mg} \mathrm{L}^{-1}$. The results were well described by the linearized Freundlich adsorption isotherm. Two constants, namely $K_{\mathrm{f}}$ and $n$, were calculated from the Freundlich equation. As per theory, $K_{\mathrm{f}}$ is indicative of the relative adsorption capacity $\left(\mathrm{mg} \mathrm{g}^{-1}\right)$ and provides a measure of the affinity of the adsorbate (metal ions). The adsorption capacity calculated from the Freundlich model was $0.75,0.90$ and $1.36 \mathrm{mg} \mathrm{g}^{-1}$ for WC, FWC and SWC, respectively. The $n$ values were $1.71,1.79$ and $1.95 \mathrm{~L} \mathrm{mg}^{-1}$ for $\mathrm{WC}, \mathrm{FWC}$ and SWC, respectively. The values of the determination coefficient, $R^{2}$, for Freundlich equations for three biosorbents were as follows: BWC 0.9862 , FWC 0.9814 and SWC 0.9828 (Table 2). Values of $R^{2}$ were close to unity for WC, FWC and SWC, thereby indicating the good efficacy of fitting Freundlich model to the equilibrium data. High values of $R^{2}$ for Temkin and Dubinin-Radushkevich isotherm showed the high goodness of fit of the equilibrium.

Very low values of energy $\left(3.13 \mathrm{~kJ}^{2} \mathrm{~mol}^{-1}\right.$ for BWC, $3.85 \mathrm{~kJ}^{2} \mathrm{~mol}^{-1}$ for FWC and $5.32 \mathrm{~kJ}^{2} \mathrm{~mol}^{-1}$ for SWC) in the present study indicated weak interactions between the copper (II) ions and biosorbents. Feng et al. (2009) deduced that the Langmuir isotherm model gave the best fit to the equilibrium data for the adsorption of copper (II) onto chemically modified orange peel prepared from hydrolysis of the grafted copolymer, which was synthesized by interaction of methyl acrylate with cross-linking orange peel. Demirbas et al. (2009) studied the adsorption 
Table 4 Kinetics models parameters for $\mathrm{Cu}$ (II) biosorption on BWC, FWC and SWC

\begin{tabular}{|c|c|c|c|c|c|c|c|}
\hline \multirow[t]{2}{*}{ Biosorbents } & \multirow[t]{2}{*}{ Experimental $q_{\mathrm{e}}\left(\mathrm{mg} \mathrm{g}^{-1}\right)$} & \multicolumn{3}{|l|}{ First-order model } & \multicolumn{3}{|l|}{ Second-order model } \\
\hline & & Theoretical $q_{\mathrm{e}}\left(\mathrm{mg} \mathrm{g}^{-1}\right)$ & $k_{1}\left(\min ^{-1}\right)$ & $R^{2}$ & Theoretical $q_{\mathrm{e}}\left(\mathrm{mg} \mathrm{g}^{-1}\right)$ & $k_{2}\left(\mathrm{~g} \mathrm{mg}^{-1} \min ^{-1}\right)$ & $R^{2}$ \\
\hline BWC & 4.31 & 2.06 & 0.014 & 0.270 & 4.91 & 0.0082 & 0.991 \\
\hline FWC & 4.43 & 2.17 & 0.016 & 0.254 & 5.05 & 0.008 & 0.991 \\
\hline SWC & 4.7 & 1.94 & 0.014 & 0.266 & 5.2 & 0.01 & 0.993 \\
\hline
\end{tabular}

Experimental $q_{\mathrm{e}}=$ amount of metal adsorbed at equilibrium calculated by equilibrium data $\left(\mathrm{mg} \mathrm{g}^{-1}\right)$

Theoretical $q_{\mathrm{e}}=$ amount of metal adsorbed at equilibrium calculated by model $\left(\mathrm{mg} \mathrm{g}^{-1}\right)$

$k_{1}$ and $k_{2}=$ rate constants for adsorption

of copper (II) ions from aqueous solutions by hazelnut shell activated carbon in batch adsorption system and equally found that adsorption equilibrium data fitted best with the Langmuir isotherm and the monolayer adsorption capacity of copper (II) ions. Wu et al. (2009) tested a natural wheat straw for removal of copper and deduced that copper (II) adsorption isotherm followed the Langmuir and Redlich-Peterson models well. Recently, Han et al. (2010) found that the equilibrium data from the adsorption of copper (II) onto citric acid modified wheat straw were fitted well by both the Freundlich and Langmuir models (maximal equilibrium quantity of copper (II) from Langmuir model was $39.17 \mathrm{mg} \mathrm{g}^{-1}\left(20^{\circ} \mathrm{C}\right)$. More lately, Pehlivan et al. (2012) utilized barley straw to remove of copper (II) ions from aqueous solutions after treatment with citric acid. Besides the finding that the optimum $\mathrm{pH}$ for the removal of copper (II) ions by citric acid treated barley straw was around $\mathrm{pH}$ 7.0, Pehlivan et al. (2012) tested the Langmuir, Freundlich, Scatchard and Dubinin-Radushkevich isotherms to model the biosorption phenomena of copper adsorption. In this study, activated carbon produced from Tunisian date stones, a low-cost agricultural by-product, by chemical activation using $\mathrm{H}_{3} \mathrm{PO}_{4}$ as an activator was used as adsorbent for the removal of copper (II) ions from aqueous solutions. To optimize the preparation method, the effect of the main process parameters (such as acid concentration, impregnation ratio and temperature of pyrolysis step) on the performances of the obtained activated carbons was studied. The optimal activated carbon was fully characterized considering its adsorption properties as well as its chemical structure and morphology. Bouhamed et al. (2012) found equilibrium data were well fitted by the Langmuir and Dubinin-Radushkevich isotherm models with a monolayer maximum adsorption capacity of $31.25 \mathrm{mg} \mathrm{g}^{-1}$ for the adsorption of copper (II) onto activated carbon prepared from Tunisian date stones. Bouhamed et al. (2012) reckoned the adsorbent they tested could be expected to be an economical product for metal ion remediation from water and wastewater.
Kinetics of adsorption

In order to determine the kinetics of copper (II) biosorption, the pseudo-first-order and pseudo-second-order kinetics models were examined. The linear plots of $\log \left(q_{\mathrm{e}}-q_{\mathrm{t}}\right)$ versus $t$ for first-order model and $t / q_{\mathrm{e}}$ versus $t$ for secondorder model were plotted for all three biosorbents. The slopes and intercepts of these curves were used to determine the pseudo-first-order and pseudo-second-order constants $k_{1}$ and $k_{2}$ and the equilibrium capacity $q_{\mathrm{e}}$. The values of constants $k_{1}, k_{2}, q_{\mathrm{e}}$ and $R^{2}$ calculated from the plots are given in Table 4 . The results showed that the pseudo-second-order equation fitted well to the data. Ucun et al. (2009) have equally found the biosorption kinetics of copper (II) onto the cone biomass of Pinus sylvestris L. to follow the secondorder kinetic model and correlate well with experimental data. Yao et al. (2010) reported that kinetic data followed the pseudo-second-order model for the biosorption of copper (II) ions onto chestnut shell, a residue of the food processing industry. Munagapati et al. (2010) tested the biosorption of copper (II) ions onto Acacia leucocephala bark powder, and kinetic studies indicated that the biosorption process of the metal ions followed well pseudo-second-order model. Recently, Blázquez et al. (2012) studied pine cone shell as an effective and efficient biosorbent for the removal of copper (II) from aqueous solutions. Their kinetics data also fitted well into the pseudo-second-order model with correlation coefficient $>0.99$.

\section{Conclusion}

From the above results, it may be inferred that BWC, FWC and SWC could be suitable low-cost adsorbents for the removal of copper (II) ions from dilute effluents. The adsorption processes were found to be strongly dependent on $\mathrm{pH}$, adsorbent dose, contact time and initial copper (II) ions concentration. The maximum removal of the copper ions was observed at an optimum acidic $\mathrm{pH}$ of 5.0. The efficiencies of formaldehyde-treated wood chips and 
sulphuric acid-treated wood chips for copper (II) ions removal were higher in the dilute solutions at a $20 \mathrm{~g} \mathrm{~L}^{-1}$ adsorbent dose than with the powdered adsorbent produced from boiled wood chips. FTIR, SEM and EDAX characterization of the adsorbents before and after the adsorption of copper (II) ions on the different adsorbents prepared in this study have, respectively, shown marked differences in morphology and chemical constitution of the native and copper (II) ions loaded adsorbents. These morphological and compositional changes provided evidence of the adsorption of copper (II) ions onto the available binding sites in the adsorbents tested in this study. Based on the adsorption capacity of BWC, FWC and SWC at equilibrium, BWC could become an attractive enough option because no chemical is required in its preparation. Wood chips are readily available in India as a process residue of timber milling activities, so the data from this work may be used in the design of adsorption units by small-scale industries having low concentrations of copper (II) ions in wastewater using batch or stirred-tank flow reactors where standard material such as activated carbon may not available. The sequel to this study is under progress and consists in analysing the potential of using the absorbents reported here in remediating copper contaminated real wastewaters.

Acknowledgments The authors express their gratitude to all the researchers whose valuable data have been adapted and have added considerable significance and substance to this paper. They are also grateful to the anonymous reviewers for their suggestions and useful criticisms which have benefited the manuscript and brought it to its present form.

\section{References}

Ahmad A, Rafatullah M, Sulaiman O, Ibrahim MH, Chii YY, Siddique BM (2009) Removal of $\mathrm{Cu}$ (II) and $\mathrm{Pb}$ (II) ions from aqueous solutions by adsorption on sawdust of Meranti wood. Desalination 247:636-646

Al-Asheh S, Banat F, Al-Omari R, Duvnjak Z (2000) Predictions of binary sorption isotherms for the sorption of heavy metals by pine bark using single isotherm data. Chemosphere 41:659-665

Anderson AR, Polansky MM, Roginski EE, Mertz W (1987) Factors affecting retention and extraction of chromium by yeast. J Agric Food Chem 26:838-861

Bai SR, Abraham ET (2001) Biosorption of Cr(VI) from aqueous solution by Rhizopus nigricans. Bioresour Technol 79:73-81

Bansal M, Garg U, Singh D, Garg VK (2009) Removal of Cr(VI) from aqueous solutions using pre-consumer processing agricultural waste: a case study of rice husk. J Hazard Mater 162:312-320

Basha S, Murthy ZVP, Jha B (2008) Biosorption of hexavalent chromium by chemically modified seaweed, Cystoseira indica. Chem Eng J 137:480-488

Benaïssa H, Elouchdi MA (2011) Biosorption of copper (II) ions from synthetic aqueous solutions by drying bed activated sludge. J Hazard Mater 194:69-78

Benyoucef S, Amrani M (2011) Adsorption of phosphate ions onto low cost Aleppo pine adsorbent. Desalination 275:231-236
Blázquez G, Martín-Lara MA, Dionisio-Ruiz E, Tenorio G, Calero M (2012) Copper biosorption by pine cone shell and thermal decomposition study of the exhausted biosorbent. J Ind Eng Chem 18:1741-1750

Bouhamed F, Elouear Z, Bouzid J (2012) Adsorptive removal of copper (II) from aqueous solutions on activated carbon prepared from Tunisian date stones: equilibrium, kinetics and thermodynamics. J Taiwan Inst Chem Eng 43:741-749

Cerino Córdova FJ, García León AM, Garcia Reyes RB, Garza González MT, Soto Regalado E, Sánchez González MN, Quezada López I (2011) Response surface methodology for lead biosorption on Aspergillus terreus. Int J Environ Sci Technol 8:695-704

Cui C, He M, Hu B (2011) Membrane solid phase microextraction with alumina hollow fiber on line coupled with ICP-OES for the determination of trace copper, manganese and nickel in environmental water samples. J Hazard Mater 187:379-385

Da'na E, Sayari A (2011) Adsorption of copper on amine-functionalized SBA-15 prepared by co-condensation: equilibrium properties. Chem Eng J 166:445-453

Dang VBH, Doan HD, Dang-Vu T, Lohi A (2009) Equilibrium and kinetics of biosorption of cadmium (II) and copper (II) ions by wheat straw. Bioresour Technol 100:211-219

Demirbas E, Dizge N, Sulak MT, Kobya M (2009) Adsorption kinetics and equilibrium of copper from aqueous solutions using hazelnut shell activated carbon. Chem Eng J 148:480-487

Dos Santos VCG, De Souza JVTM, Tarley CRT, Caetano J, Dragunski DC (2011) Copper ions adsorption from aqueous medium using the biosorbent sugarcane bagasse in natura and chemically modified. Water Air Soil Pollut 216:351-359

Feng N, Guo X, Liang S (2009) Adsorption study of copper (II) by chemically modified orange peel. J Hazard Mater 164:1286-1292

Gao H, Liu Y, Zeng G, Xu W, Li T, Xia W (2008) Characterization of $\mathrm{Cr}(\mathrm{VI})$ removal from aqueous solutions by a surplus agricultural waste-rice straw. J Hazard Mater 150:446-452

Garg VK, Gupta R, Kumar R, Gupta RK (2004) Adsorption of chromium from aqueous solution on treated sawdust. Bioresour Technol 92:79-81

Grimm A, Zanzi R, Björnbom E, Cukierman AL (2008) Comparison of different types of biomasses for copper biosorption. Bioresour Technol 99:2559-2565

Gupta VK, Carrott PJM, Ribeiro Carrott MML, Suhas (2009) Lowcost adsorbents: growing approach to wastewater treatment-a review. Crit Rev Environ Sci Technol 39:783-842.

Han R, Zhang L, Song C, Zhang M, Zhu H, Zhang L (2010) Characterization of modified wheat straw, kinetic and equilibrium study about copper ion and methylene blue adsorption in batch mode. Carbohydr Polym 79:1140-1149

Hashem A, Adam E, Hussein HA, Sanousy MA, Ayoub A (2013) Bioadsorption of $\mathrm{Cd}$ (II) from contaminated water on treated sawdust: adsorption mechanism and optimization. J Water Resour Protect 5:82-90

Kapoor A, Viraraghvan T (1997) Biosorption of heavy metals on Aspergillus niger: effect of pretreatment. Bioresour Technol 63:109-113

Kour J, Homagai PL, Pokhrel MR, Ghimire KN (2012) Adsorptive separation of metal ions with surface modified Desmostachya bipinnata. Nepal J Sci Technol 13:101-106

Kumar U, Bandyopadhyay M (2006) Fixed bed column study for $\mathrm{Cd}(\mathrm{II})$ removal from wastewater using treated rice husk. J Hazard Mater 129:253-259

Larous S, Meniai AH, Lehocine MB (2005) Experimental study of the removal of copper from aqueous solutions by adsorption using sawdust. Desalination 185:483-490

Lu YD, Wu WL, Lin S, You RY, Wu ZH (2013) Removal of Cr(VI) from aqueous solution using Camellia oleifera Abel shells. Mater Sci Forum 743-744:463-468 
Malkoc E, Nuhoglu Y (2007) Potential of tea factory waste for chromium (VI) removal from aqueous solutions: thermodynamic and kinetic studies. Sep Purif Technol 54:291-298

McKay G, Ho YS, Ng JCY (1999) Biosorption of copper from wastewaters: a review. Sep Purif Rev 28:87-125

Memon SQ, Bhanger MI, Khuhawar MY (2005) Preconcentration and separation of $\mathrm{Cr}(\mathrm{III})$ and $\mathrm{Cr}(\mathrm{VI})$ using sawdust as a sorbent. Anal Bioanal Chem 383:619-624

Mohan D, Pittman CU Jr, Bricka M, Smith F, Yancey B, Muhammad J, Steele PH, Alexandre-Franco MF, Gomez-Serrano V, Gong H (2007) Sorption of arsenic, cadmium, and lead by chars produced from fast pyrolysis of wood and bark during bio-oil production. J Colloid Interface Sci 310:57-73

Mudhoo A, Seenauth PD (2011) Biosorption characteristics of Cr6+ from aqueous solutions by Pinus Sylvestris L. timber fillings. Rasayan J Chem 4:56-65

Munagapati VS, Yarramuthi V, Nadavala SK, Alla SR, Abburi K (2010) Biosorption of $\mathrm{Cu}(\mathrm{II}), \mathrm{Cd}(\mathrm{II})$ and $\mathrm{Pb}(\mathrm{II})$ by Acacia leucocephala bark powder: kinetics, equilibrium and thermodynamics. Chem Eng J 157:357-365

Musyoka S, Ngila C, Moodley B, Kindness A, Petrik L, Greyling C (2011) Oxolane-2,5-dione modified electrospun cellulose nanofibers for heavy metals adsorption. J Hazard Mater 192:922-927

Ofomaja AE, Naidoo EB (2011) Biosorption of copper from aqueous solution by chemically activated pine cone: a kinetic study. Chem Eng J 175:260-270

Ofomaja AE, Unuabonah EI, Oladoja NA (2010) Competitive modeling for the biosorptive removal of copper and lead ions from aqueous solution by Mansonia wood sawdust. Bioresour Technol 101:3844-3852

Owlad M, Aroua MK, Wan Daud WMA (2010) Hexavalent chromium adsorption on impregnated palm shell activated carbon with polyethyleneimine. Bioresour Technol 101:5098-5103

Pehlivan E, Altun T, Parlayici Ş (2012) Modified barley straw as a potential biosorbent for removal of copper ions from aqueous solution. Food Chem 135:2229-2234

Rafatullah M, Sulaiman O, Hashim R, Ahmad A (2009) Adsorption of copper (II), chromium (III), nickel (II) and lead (II) ions from aqueous solutions by meranti sawdust. J Hazard Mater 170: 969-977

Rameshraja D, Srivastava VC, Kushwaha JP, Mall ID (2012) Quinoline adsorption onto granular activated carbon and bagasse fly ash. Chem Eng J 181-182:343-351

Salam MA, Makki MSI, Abdelaal MYA (2011) Preparation and characterization of multi-walled carbon nanotubes/chitosan nanocomposite and its application for the removal of heavy metals from aqueous solution. J Alloys Compd 509:2582-2587

Tangsathitkulchai C, Ngernyen Y, Tangsathitkulchai M (2009) Surface modification and adsorption of eucalyptus wood-based activated carbons: effects of oxidation treatment, carbon porous structure and activation method. Korean J Chem Eng 26: $1341-1352$

Tirgar A, Golbabaei F, Hamedi J, Nourijelyani K (2011) Removal of airborne hexavalent chromium using alginate as a biosorbent. Int J Environ Sci Technol 8:237-244

Ucun H, Aksakal O, Yildiz E (2009) Copper (II) and zinc (II) biosorption on Pinus sylvestris L. J Hazard Mater 161: 1040-1045

Veglio F, Beolchini F (1997) Removal of metals by biosorption: a review. Hydrometallurgy 44:301-316

Velazquez-Jimenez LH, Pavlick A, Rene Rangel-Mendez J (2013) Chemical characterization of raw and treated agave bagasse and its potential as adsorbent of metal cations from water. Ind Crops Prod 43:200-206

Vinodhini V, Das N (2009) Mechanism of Cr(VI) biosorption by neem sawdust. Am Eur J Sci Res 4:324-329

Wan Maznah WO, Al-Fawwaz AT, Surif M (2012) Biosorption of copper and zinc by immobilised and free algal biomass, and the effects of metal biosorption on the growth and cellular structure of Chlorella sp. and Chlamydomonas sp. isolated from rivers in Penang, Malaysia. J Environ Sci 24:1386-1393

Wan Ngah WS, Hanafiah MAKM (2008) Adsorption of copper on rubber (Hevea brasiliensis) leaf powder: kinetic, equilibrium and thermodynamic studies. Biochem Eng J 3:521-530

Witek-Krowiak A, Szafran RG, Modelski S (2011) Biosorption of heavy metals from aqueous solutions onto peanut shell as a lowcost adsorbent. Desalination 265:126-134

Wu Y, Zhang L, Gao C, Ma J, Ma X, Han R (2009) Adsorption of copper ions and methylene blue in a single and binary system on wheat straw. J Chem Eng Data 54:3229-3234

Yao Z-Y, Qi J-H, Wang L-H (2010) Equilibrium, kinetic and thermodynamic studies on the biosorption of $\mathrm{Cu}$ (II) onto chestnut shell. J Hazard Mater 174:137-143

Yeh T, Lin C, Chen C, Pan C (2011) Heavy metal biosorption properties of four harvested macrophytes. J Hazard Toxic Radioact Waste 15:108-113

Zamani AA, Shokri R, Yaftian MR, Parizanganeh AH (2013) Adsorption of lead, zinc and cadmium ions from contaminated water onto Peganum harmala seeds as biosorbent. Int J Environ Sci Technol 10:93-102

Zhang N, Qiu H, Si Y, Wang W, Gao J (2011) Fabrication of highly porous biodegradable monoliths strengthened by graphene oxide and their adsorption of metal ions. Carbon 49:827-837

Zhu B, Fan T, Zhang D (2008) Adsorption of copper ions from solution by citric acid modified soybean straw. J Hazard Mater 153:300-308 